\title{
Special Issue in Honour of Dr R J W Rees, CMG
}

\section{A Dedication}

For the past thirty years Dr RJW Rees, known to his friends and colleagues as Dick Rees, has been closely associated in so many aspects of the international scientific battle against Mycobacterium leprae.

It is in recognition and appreciation of his inestimable contribution to this battle that LEPRA has dedicated this special issue of Leprosy Review to him. It will not only provide up to date information on all aspects of leprosy research in which Dick Rees is particularly interested, but also should inspire others with his determination, drive and energy until the battle is won and leprosy is no longer feared by people who live where the disease is still endemic. 